\title{
Prevalence and extent of infarct and microvascular obstruction following different reperfusion therapies in ST-elevation myocardial infarction
}

Jamal N Khan ${ }^{1,2}$, Naveed Razvi ${ }^{1,2}$, Sheraz A Nazir ${ }^{1,2}$, Anvesha Singh ${ }^{1,2}$, Nicholas GD Masca ${ }^{1,2}$, Anthony H Gershlick ${ }^{1,2}$, lain Squire ${ }^{1,2}$ and Gerry P McCann ${ }^{1,2^{*}}$

\begin{abstract}
Background: Microvascular obstruction (MVO) describes suboptimal tissue perfusion despite restoration of infarct-related artery flow. There are scarce data on Infarct Size (IS) and MVO in relation to the mode and timing of reperfusion. We sought to characterise the prevalence and extent of microvascular injury and IS using Cardiovascular magnetic resonance (CMR), in relation to the mode of reperfusion following acute ST-Elevation Myocardial Infarction (STEMI).

Methods: CMR infarct characteristics were measured in 94 STEMI patients (age $61.0 \pm 13.1$ years) at 1.5 T. Seventy-three received reperfusion therapy: primary percutaneous coronary-intervention ( $\mathrm{PPCl}, \mathrm{n}=47)$; thrombolysis $(\mathrm{n}=12)$; rescue $\mathrm{PCl}(\mathrm{R}-\mathrm{PCl}, \mathrm{n}=8)$, late $\mathrm{PCl}(\mathrm{n}=6)$. Twenty-one patients presented late ( $>12$ hours) and did not receive reperfusion therapy.

Results: IS was smaller in PPCI (19.8 $\pm 13.2 \%$ of LV mass) and thrombolysis (15.2 $\pm 10.1 \%)$ groups compared to patients in the late $\mathrm{PCl}(40.0 \pm 15.6 \%)$ and $\mathrm{R}-\mathrm{PCl}(34.2 \pm 18.9 \%)$ groups, $\mathrm{p}<0.001$. The prevalence of MVO was similar across all groups and was seen at least as frequently in the non-reperfused group (15/21, [76\%] $\vee 33 / 59$, [56\%], $p=0.21)$ and to a similar magnitude (1.3 (0.0-2.8) $\vee 0.4[0.0-2.9] \% \mathrm{LV}$ mass, $\mathrm{p}=0.36)$ compared to patients receiving early reperfusion therapy. In the 73 reperfused patients, time to reperfusion, ischaemia area at risk and TIMI grade post-PCI were the strongest independent predictors of IS and MVO.

Conclusions: In patients with acute STEMI, CMR-measured MVO is not exclusive to reperfusion therapy and is primarily related to ischaemic time. This finding has important implications for clinical trials that use CMR to assess the efficacy of therapies to reduce reperfusion injury in STEMI.
\end{abstract}

Keywords: Cardiovascular magnetic resonance, Myocardial infarction, Microvascular obstruction, Primary angioplasty, Thrombolysis, Reperfusion, Ischaemia-reperfusion injury, Reperfusion injury

\section{Background}

In the setting of acute ST-segment elevation myocardial infarction (STEMI), microvascular obstruction (MVO) describes suboptimal tissue perfusion despite restoration of flow in the infarct-related artery (IRA). MVO is generally thought to be related primarily to reperfusion injury [1-3]. Cardiovascular magnetic resonance (CMR)

\footnotetext{
* Correspondence: gerry.mccann@uhl-tr.nhs.uk

'Department of Cardiovascular Sciences, University of Leicester, Glenfield Hospital, Groby Road, Leicester LE3 9QP, UK

${ }^{2}$ NIHR Leicester Cardiovascular Biomedical Research Unit, Glenfield Hospital, Groby Road, Leicester LE3 9QP, UK
}

\section{Ciomed Central}

(c) 2014 Khan et al.; licensee BioMed Central Ltd. This is an Open Access article distributed under the terms of the Creative Commons Attribution License (http://creativecommons.org/licenses/by/4.0), which permits unrestricted use, distribution, and reproduction in any medium, provided the original work is properly credited. The Creative Commons Public Domain Dedication waiver (http://creativecommons.org/publicdomain/zero/1.0/) applies to the data made available in this article unless otherwise stated. provides unique characterisation of myocardial injury post STEMI [4].

CMR-measured MVO correlates strongly with STsegment resolution in patients undergoing primary percutaneous coronary intervention (PPCI) but relatively weakly with myocardial blush-grade and poorly with TIMI flow [5]. Larger infarcts on CMR are consistently associated with larger ventricular volumes, lower ejection fraction and greater MVO [6], which occurs in $40-60 \%$ of patients treated by primary percutaneous coronary intervention (PPCI). CMR-derived infarct size (IS) $[4,7]$ and MVO $[8,9]$ 
are powerful predictors of adverse remodelling and prognosis post STEMI.

The European Society of Cardiology (ESC) [10] advocates four reperfusion strategies for acute STEMI: PPCI, thrombolysis, rescue coronary angioplasty (R-PCI) and late PCI ( $>12$ hours after symptoms). There is a paucity of data on the prevalence and extent of MVO following STEMI, with different reperfusion therapies $[11,12]$, and in particular in patients who do not receive any reperfusion therapy.

This study aimed to characterise the prevalence and extent of microvascular injury (MVO) and IS using CMR, in relation to the mode of reperfusion following STEMI.

\section{Methods}

\section{Subjects and reperfusion therapy}

Ninety-seven patients presenting to a single regional cardiac centre with a first acute STEMI from Jan 2010 to April 2012 were included. Diagnosis of STEMI was made according to ACCF/AHA and ESC definitions [10]. Seventy-six patients who received one of the four advocated reperfusion strategies were recruited prospectively in a study assessing left ventricular (LV) remodeling (Figure 1). Three patients were excluded due to inability to complete CMR. The remaining 73 patients were treated as follows: PPCI $(\mathrm{n}=47)$, thrombolysis $(\mathrm{n}=12)$, R-PCI $(\mathrm{n}=8)$, late PCI $(n=6)$. Reperfusion therapy was decided at the point of first medical contact according to local guidelines. Late PCI patients underwent PCI $>12$ hours after symptom onset (TTR) in the presence of electrocardiographic or clinical evidence of ongoing ischaemia. Twenty-one consecutive STEMI patients who presented late $(>12$ hours after symptom onset) and were symptom-free on arrival and did not receive reperfusion therapy formed the non-reperfused cohort. These patients underwent clinical CMR to assess myocardial viability. The local research ethics committee approved the study and prospectively recruited patients provided written consent prior to participation.

'Early-reperfused' patients were defined as those undergoing successful initial reperfusion within 12 hours of symptoms (PPCI, successful thrombolysis). Thrombolysis was performed in patients presenting to non-PCI capable regional hospitals using tissue plasminogen-activator analogues. Successful thrombolysis was defined as symptom resolution and $\geq 50 \%$ resolution of ST-segment elevation within 90 minutes, and was followed by transfer to our centre for coronary angiography. Immediate transfer for R-PCI was undertaken for thrombolysis failure. Time to reperfusion (TTR) was measured as the time between symptom onset and successful restoration of IRA flow for PCI-related revascularisation, and time until administration of successful thrombolytic therapy for thrombolysed patients.

\section{Angiographic assessment}

The Thrombolysis in Myocardial Infarction (TIMI) scoring system was used to quantify angiographic IRA flow [13]. The degree of collateral flow to the IRA territory was quantified using the Rentrop Score (Grade 0: absent visible collateral flow; Grade 1: IRA side-branches only filled; Grade 2: partial filling of main IRA vessel; Grade 3: IRA completely filled by collaterals) [14].

\section{CMR image acquisition}

CMR was performed on all subjects during the index admission on a $1.5 \mathrm{~T}$ scanner (Siemens Avanto, Erlangen,

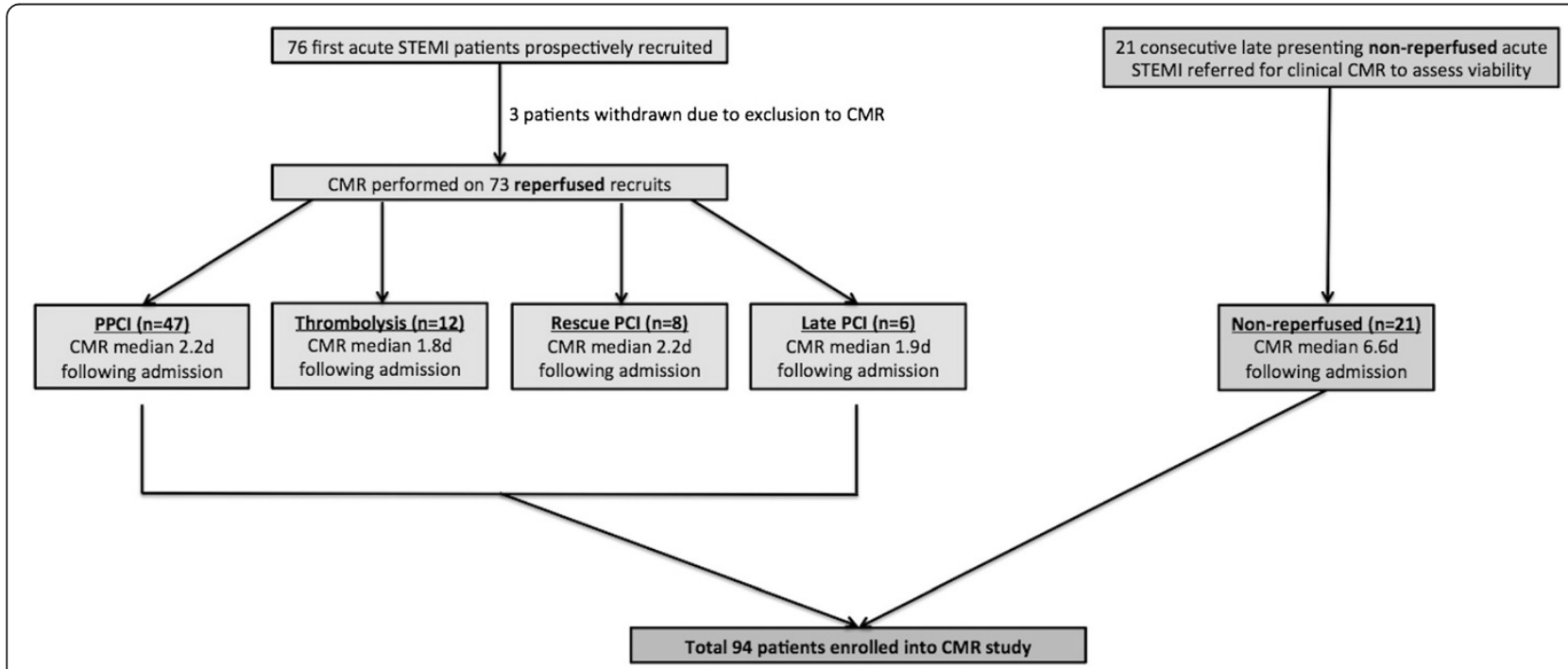

Figure 1 Study recruitment. 
Germany) with retrospective electrocardiogram gating and a 6-channel phased-array cardiac receiver coil supervised by a cardiologist with a subspecialist interest in CMR (Figure 2). Cine imaging with steady-state free precession and Late Gadolinium Enhancement (LGE) imaging were performed in long-axis views and contiguous shortaxis slices covering the entire LV. LGE images were acquired 10-15 minutes after contrast administration using a segmented inversion-recovery gradient-echo sequence. The inversion time was progressively adjusted to null unaffected myocardium. T2-weighted short-tau inversion recovery (T2w-STIR) imaging with coil signal intensity correction was performed on the 73 prospectively recruited reperfused subjects and not on the 21 non-reperfused patients since they underwent a routine clinical CMR protocol to assess for viability.

\section{CMR image analysis}

Analysis was performed offline blinded to patient details using QMass 7.1 (Medis, Leiden, Netherlands) by two experienced observers (JNK, NAR with 3 years CMR experience each). LV volumes and function were calculated as previously described [5]. Ischaemic area at risk ([AAR] oedema) was defined semi-automatically as areas of hyperenhancement $\geq 2$ standard deviations above the signal intensity of unaffected myocardium. Infarct zone was defined semi-automatically on LGE imaging using the Full-Width Half-Maximum (FWHM) technique [15]. MVO was defined as areas of hypoenhancement within the infarct zone and was included in the assessed IS. AAR, IS and MVO were expressed as a percentage of LV end-diastolic mass (\%LVM) and LV volumes were indexed by body-surface area.

\section{Statistical analysis}

Normality was assessed using the Kolmogorov-Smirnov test, histograms and Q-Q plots. Normally distributed data were expressed as mean \pm standard deviation and analysed using ANOVA and independent t-tests. Non-normally distributed variables were expressed as median (25\%-75\% interquartile range) and analysed using Mann-Whitney U-tests. Chi-squared analysis was used to compare MVO prevalence between cohorts. The association between time from symptom onset to revascularisation (TTR), AAR, time to CMR after admission, left anterior descending artery infarct related artery (LAD IRA), TIMI flow pre and post-PCI and revascularisation method with IS and MVO were assessed for reperfused patients using univariate regression. Predictors with $\mathrm{p}<0.1$ underwent stepwise multivariate analysis. Since categorical and continuous variables were used, the strength of variables was expressed according to their p-value. CMR markers were corrected for TTR using ANCOVA. Reproducibility of CMR analysis was assessed using two-way mixed-effect intraclass correlation coefficient for absolute agreement (ICC) for a subset of 10 randomly chosen studies. Statistical tests were performed on SPSS version 20. $\mathrm{p}<0.05$ was considered significant.

\section{Results}

\section{Baseline characteristics}

Baseline demographics and angiography findings are summarised in Table 1. Diabetes was more prevalent in

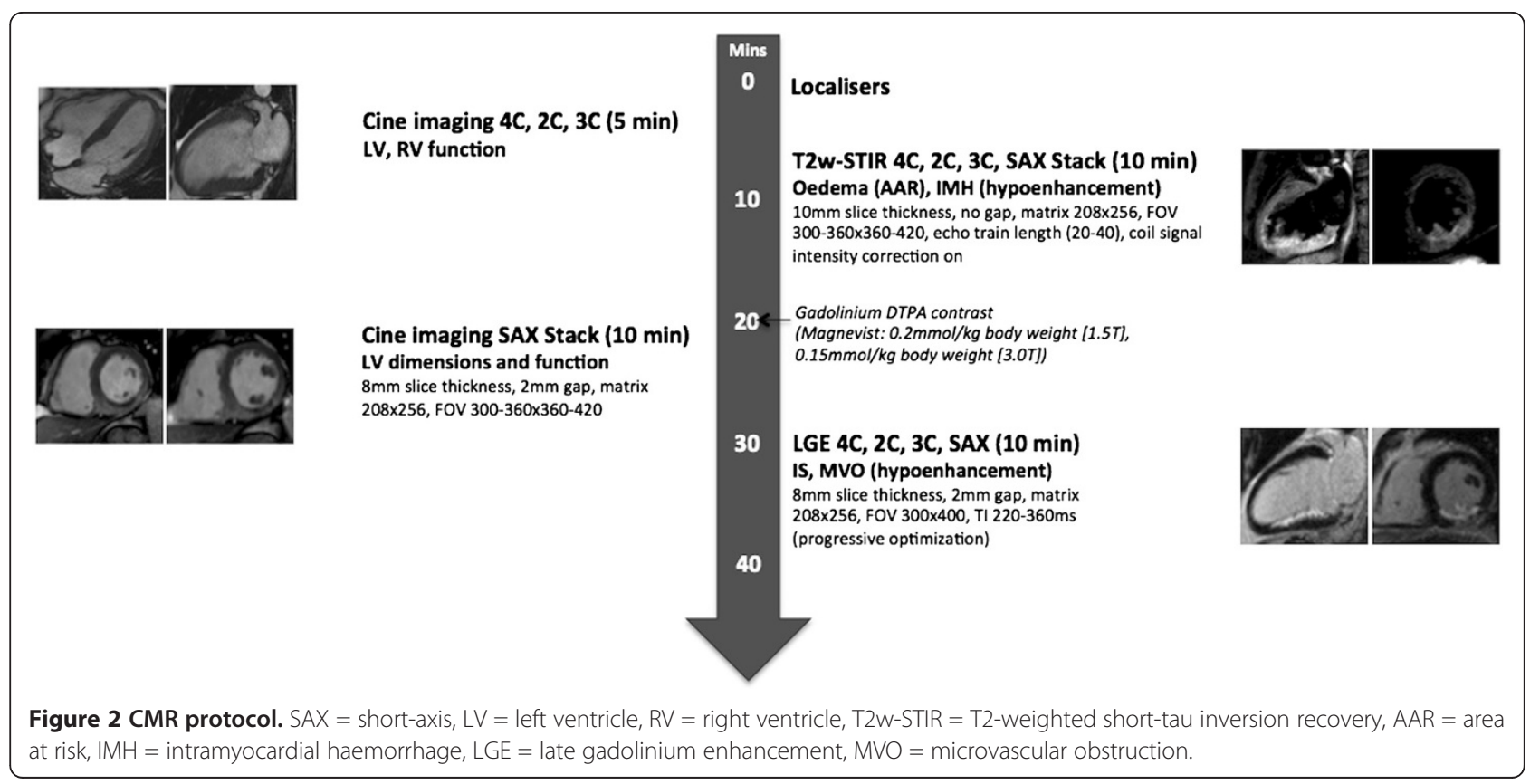


Table 1 Baseline demographics and angiographic data by reperfusion therapy

\begin{tabular}{|c|c|c|c|c|c|c|}
\hline Variable & $\begin{array}{l}\text { Group 1, } n=47 \\
\text { (PPCI) }\end{array}$ & $\begin{array}{l}\text { Group 2, } n=12 \\
\text { (Thrombolysis) }\end{array}$ & $\begin{array}{l}\text { Group 3, n= } 8 \\
\text { (Rescue-PCI) }\end{array}$ & $\begin{array}{l}\text { Group 4, } n=6 \\
\text { (Late } P C I \text { ) }\end{array}$ & $\begin{array}{l}\text { Group 5, } \mathrm{n}=21 \\
\text { (Non-reperfused) }\end{array}$ & $p$ \\
\hline Age (years) & $60.5 \pm 12.3$ & $59.3 \pm 10.6$ & $59.5 \pm 12.5$ & $54.7 \pm 12.1$ & $65.6 \pm 16.2$ & 0.37 \\
\hline Male sex $(n, \%)$ & $42(89.7)$ & $11(91.7)$ & $8(100)$ & $5(83.3)$ & $16(76.2)$ & 0.21 \\
\hline Current smoking $(n, \%)$ & $23(48.9)$ & $6(50)$ & $3(37.5)$ & $1(16.7)$ & $9(42.9)$ & 0.64 \\
\hline Diabetes (n,\%) & $2(4.3)$ & $1(0)$ & $0(0)$ & $0(0)$ & $6(28.6)$ & 0.01 \\
\hline Angina $(n, \%)$ & $2(4.3)$ & $1(8.3)$ & $0(0)$ & $0(0)$ & $5(23.8)$ & 0.07 \\
\hline TTR (mins) & $150(120-240)$ & $210(75-300)$ & $285(211.25-345)$ & $1113(810-1342)$ & $\mathrm{n} / \mathrm{a}$ & $<0.001$ \\
\hline Peak CK (iU/L) & $875(415.3-2061)$ & $1034(334.5-1384)$ & $3002(758-5045.5)$ & $2633(1073.3-5852)$ & $1033(87.8-2220.3)$ & 0.88 \\
\hline Angiography & & & & & $(n=15)$ & \\
\hline LAD IRA $(n, \%)$ & $19(40.4)$ & $6(50)$ & $4(50)$ & $6(100)$ & $8(53.3)$ & 0.10 \\
\hline LCX IRA $(n, \%)$ & $8(17.0)$ & $0(0)$ & $1(12.5)$ & $0(0)$ & $4(26.7)$ & 0.10 \\
\hline RCA IRA $(n, \%)$ & $20(42.6)$ & $6(50)$ & $3(37.5)$ & $0(0)$ & $3(20.0)$ & 0.10 \\
\hline Multi-vessel disease $(n, \%)$ & $16(34)$ & $4(33.3)$ & $1(12.5)$ & $0(0)$ & $5(33.3)$ & 0.38 \\
\hline Rentrop Score & $0(0-1)$ & $0(0-0)$ & $0(0-0)$ & $0(0-)$ & $0(0-0)$ & 0.51 \\
\hline Rentrop B (Grd 2-3, n,\%) & $6(13.3)$ & $0(0)$ & $0(0)$ & $1(16.7)$ & $1(6.7)$ & 0.50 \\
\hline TIMI flow pre 0-II $(n, \%)$ & $43(95.6)$ & $6(83.3)$ & $8(100)$ & $5(83.3)$ & $12(80.0)$ & 0.27 \\
\hline TIMI flow post III $(n, \%)$ & $31(68.9)$ & $9(58.3)$ & $4(50)$ & $4(66.7)$ & $\mathrm{n} / \mathrm{a}$ & 0.82 \\
\hline GPIlb/Illa inhibitor use & $18(41.9)$ & $0(0)$ & $3(37.5)$ & $2(40)$ & $\mathrm{n} / \mathrm{a}$ & 0.39 \\
\hline Thrombectomy catheter? & $20(42.6)$ & $0(0)$ & $5(62.5)$ & $1(16.7)$ & $n / a$ & 0.01 \\
\hline
\end{tabular}

Angiographic data available for 88/94 patients (angiography not performed in 6/21 non-reperfused patients).

$T \mathrm{~T}=$ time from symptom onset to revascularisation, $\mathrm{PPCl}=$ primary percutaneous coronary angioplasty, IRA = infarct-related artery, LAD = left anterior descending artery, LCX = left circumflex artery, RCA = right coronary artery, TIMI = thrombolysis in myocardial infarction, (pre) = TIMI score at start of coronary angiogram, (post) = TIMI score post-PCI, GPIIb/IIla = glycoprotein Ilb/llla inhibitor.

the non-reperfused group and TTR was longer in late PCI patients than the other groups. TIMI flow grade in successfully thrombolysed patients at the start of angiography was higher than in the other cohorts. Fifteen (71.4\%) non-reperfused patients underwent coronary angiography (pre-CMR in 6 patients; post-CMR in 9). In 12 (80\%) of these patients, TIMI flow-grade was abnormal (TIMI-0 in 6 patients, TIMI-1 in 4, TIMI-2 in 2).

\section{CMR data}

CMR data are shown in Table 2. The median time from admission to CMR was longer in the non-reperfused cohort compared with the other reperfusion strategies.

\section{Volumes and function}

LV volumes were higher and LV ejection fraction lower in the late-PCI, R-PCI groups and non-reperfused cohorts compared with the PPCI and thrombolysed patients. In reperfused patients, when corrected for TTR, the differences in LVESVI and LVEF were no longer significant (Table 2).

\section{IS, AAR and MVO}

IS differed across the five study cohorts, being higher in R-PCI and late PCI groups compared with PPCI and thrombolysed patients (late PCI vs PPCI $\mathrm{p}=0.015$, late
PCI vs thrombolysis $\mathrm{p}=0.008$, late PCI vs non-reperfused $\mathrm{p}=0.014$, $\mathrm{R}-\mathrm{PCI}$ vs thrombolysis $\mathrm{p}=0.06$ on subgroup analysis). When corrected for TTR, the differences in IS in reperfused patients were no longer statistically significant $(\mathrm{p}=0.33)$.

AAR was significantly larger in the late PCI group compared with those undergoing the 3 alternative reperfusion techniques $(\mathrm{p}<0.01$ compared with each strategy on subgroup analysis). When corrected for TTR, differences in AAR were only of borderline statistical significant $(\mathrm{p}=0.054)$.

The prevalence of MVO was similar in the 5 cohorts. There was a trend towards the extent (\% of LV mass) of MVO being greatest in the late PCI group, followed by non-reperfused and R-PCI patients. When corrected for TTR, the difference in MVO with the four reperfusion techniques was not statistically significant. Representative CMR and angiography images from patients in the 5 cohorts are shown in Figure 3.

\section{Interobserver and intraobserver agreement of CMR analysis} of infarct characteristics

Interobserver agreement for IS, MVO, AAR and MSI was excellent, with ICCs of $0.905,0.958,0.888$ and 0.931 respectively. Intraobserver agreement was also excellent, with ICCs as follows: (a) observer 1: IS (0.980), MVO 
Table 2 CMR data by reperfusion therapy

\begin{tabular}{|c|c|c|c|c|c|c|c|}
\hline Variable & $\begin{array}{l}\text { Group 1, } \\
\mathrm{n}=47 \text { (PPCI) }\end{array}$ & $\begin{array}{l}\text { Group 2, } \mathrm{n}=12 \\
\text { (Thrombolysis) }\end{array}$ & $\begin{array}{l}\text { Group 3, } \mathrm{n}=8 \\
\text { (Rescue-PCI) }\end{array}$ & $\begin{array}{l}\text { Group 4, } \mathrm{n}=6 \\
\text { (Late PCI) }\end{array}$ & $\begin{array}{l}\text { Group 5, } \mathrm{n}=21 \\
\text { (Non-reperfused) }\end{array}$ & $p$ & $\begin{array}{l}p \text { (corrected } \\
\text { for TTR) }\end{array}$ \\
\hline Time admission-CMR (d) & $1.8(1.1-2.6)$ & $2.2(1.3-2.6)$ & $1.9(1.4-3.8)$ & $1.9(1.5-3.6)$ & $6.6(4.8-11.0)$ & $<0.001$ & - \\
\hline LVEDVI (ml/m2) & $91.6(84.9-102.7)$ & $83.8(76.1-107.6)$ & 99.7 (88.5-116.6) & $99.3(83.7-106.7)$ & $98.0(88.1-125.0)$ & $0.08^{\mathrm{a}}$ & $0.44^{\mathrm{a}}$ \\
\hline LVESVI (ml/m2) & $51.3(47.5-62.6)$ & $55.1(38.1-80.6)$ & $63.1(48.9-79.7)$ & $64.1(52.8-71.6)$ & $61.1(54.0-83.6)$ & $0.03^{\mathrm{a}}$ & $0.39^{a}$ \\
\hline LVMI (g/m2) & $50.0(47.4-55.7)$ & $46.3(42.8-67.3)$ & $50.9(43.2-56.7)$ & $48.8(42.0-59.6)$ & $58.0(50.4-63.9)$ & $0.24^{\mathrm{a}}$ & $0.96^{\mathrm{a}}$ \\
\hline LVEF (\%) & $42.0 \pm 7.9$ & $43.3 \pm 7.5$ & $36.5 \pm 9.4$ & $37.1 \pm 10.0$ & $35.0 \pm 11.3$ & 0.02 & 0.34 \\
\hline AAR (\%LVM) & $48.6(35.9-66.5)$ & $63.0(49.7-65.3)$ & $56.8(37.6-67.7)$ & $89.2(77.2-98.1)$ & $\mathrm{n} / \mathrm{a}$ & 0.001 & 0.05 \\
\hline IS (\%LVM) & $25.4 \pm 16.0$ & $20.5 \pm 12.5$ & $39.8 \pm 21.8$ & $47.4 \pm 22.7$ & $23.8 \pm 11.5$ & $0.02^{\mathrm{a}}$ & $0.33^{\mathrm{a}}$ \\
\hline MVO presence (\%) & $26(55.3 \%)$ & 7 (58.3\%) & $5(62.5 \%)$ & $6(100 \%)$ & $15(71.4 \%)$ & NS & - \\
\hline MVO (\%LVM) & $0.5(0.0-3.3)$ & $0.2(0.0-3.9)$ & $1.2(0.0-4.6)$ & $6.4(1.0-14.8)$ & $1.3(0.0-2.8)$ & 0.08 & 0.37 \\
\hline
\end{tabular}

$\mathrm{PPCl}=$ primary percutaneous coronary angioplasty, $\mathrm{LVEDVI}=$ left ventricular end-diastolic volume index, LVESVI = left ventricular end-systolic volume index, LVMI = left ventricular end-diastolic mass index, LVEF = left ventricular ejection-fraction, AAR = ischaemic area at risk (\%LV mass), IS = infarct size (\%LV mass), MSI = myocardial salvage index (\%), MVO = microvascular obstruction (\%LV mass).

a analysed using Log10 transformed data.

(0.984), AAR (0.946), MSI (0.937), and (b) observer 2: IS (0.991), MVO (0.991), AAR (0.948), MSI (0.982).

\section{Predictors of IS and MVO in patients receiving reperfusion therapy}

In reperfused patients $(n=73)$, univariate predictors of IS were TTR, AAR, LAD IRA, reperfusion method, TIMI grade post-PCI and time from admission to CMR. In a stepwise multivariate model including all of the above plus TIMI grade pre-PCI, independent predictors of IS were TTR, AAR and TIMI grade post-PCI (model $\mathrm{R}^{2}=$ 0.41 , Table 3).
Univariate predictors of MVO extent were TTR, AAR, reperfusion method and TIMI grade pre-PCI (Table 4). In a multivariate model including TTR, AAR, reperfusion method, TIMI-grade pre-PCI and TIMI-grade post-PCI, independent predictors of $\mathrm{MVO}$ were AAR, TIMI grade post-PCI and TTR (model $R^{2}=0.23$, Table 4 ).

\section{IS and MVO in early $v$ non-reperfused patients}

The 59 patients receiving PPCI or successful lysis $(<12 \mathrm{~h})$ were grouped together as the 'early-reperfused' group for comparison with the non-reperfused group $(\mathrm{n}=21)$ and results are shown in Table 5. LV volumes were higher and
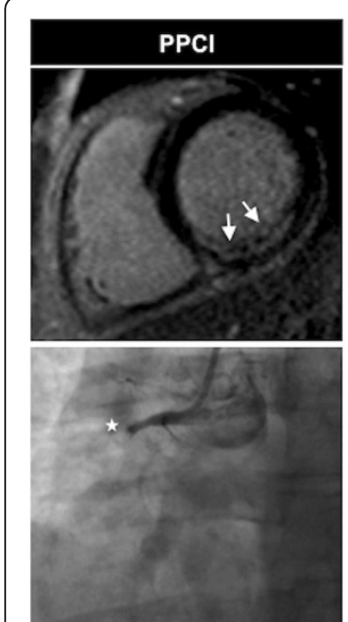

TTR (mins): $\quad 120$

LVEDVI $\left(\mathrm{ml} / \mathrm{m}^{2}\right): \quad 96$.

LVEF (\%):

IS (\%LV):

MVO (\% LV):
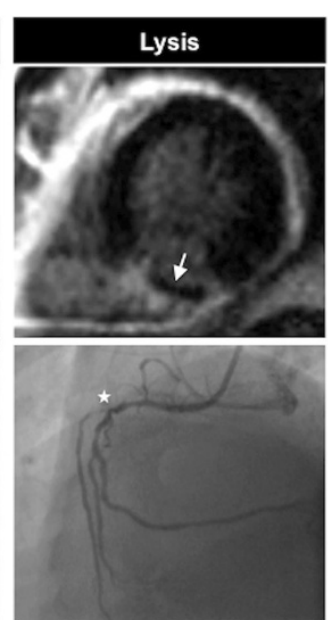

TTR (mins): $\quad 300$

$\begin{array}{ll}\text { LVEDVI }\left(\mathrm{ml} / \mathrm{m}^{2}\right): & 110.8 \\ \text { LVEF }(\%): & 43.8\end{array}$

IS (\%LV):

MVO (\% LV)
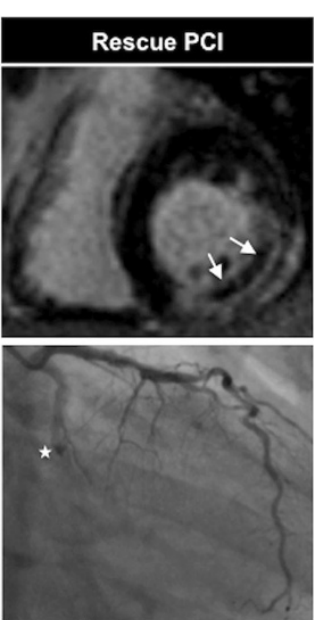

TTR (mins): $\quad 413$ LVEDVI $\left(\mathrm{ml} / \mathrm{m}^{2}\right): \quad 77.7$ LVEF (\%): IS (\%LV): MVO (\% LV)
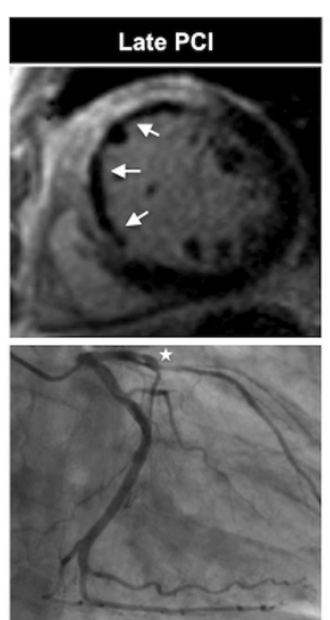

TTR (mins): $\quad 1300$ LVEDVI $\left(\mathrm{ml} / \mathrm{m}^{2}\right): \quad 127.2$ LVEF (\%): IS (\%LV): MVO (\% LV)
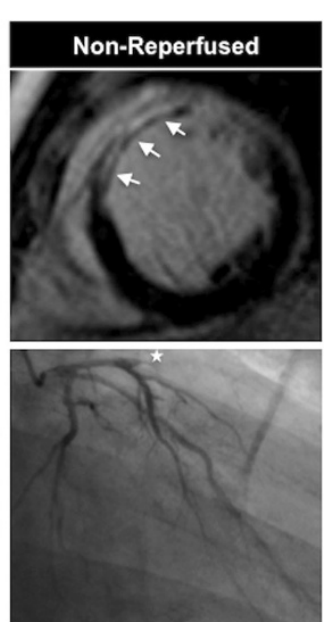

TTR (mins): n/a LVEDVI $\left(\mathrm{ml} / \mathrm{m}^{2}\right): \quad 96.0$ LVEF (\%): $\quad 30.7$ $\begin{array}{ll}\text { IS (\%LV): } & 25.7 \\ \text { MVO (\% LV): } & 2.1\end{array}$

Figure 3 Representative images of LGE CMR and coronary anatomy at the start of angiography in the cohorts. Top row: CMR late gadolinium images from a patient within each of the 5 study cohorts, demonstrating infarct (enhancement); microvascular obstruction (arrow) evident as hypointense areas within infarct. Middle row: coronary angiography images at the start of angiography in the same patients demonstrating infarct related artery; white star denotes culprit lesion (right coronary artery in PPCl and lysis patient, left circumflex in rescue-PCl patient, left anterior descending artery in late $\mathrm{PCl}$ and non-reperfused patient). Bottom row: Time from symptoms to revascularisation (TTR) and CMR data for the same patients. 
Table 3 Predictors of Infarct Size (IS) in reperfused patients

\begin{tabular}{lllll}
\hline Dependent variable for IS & $\mathbf{r}$ & $\mathbf{R}^{\mathbf{2}}$ & $\mathbf{B}$ & $\mathbf{p}$ \\
\hline Univariate & & & & \\
TTR (mins) ${ }^{\mathrm{a}}$ & 0.47 & 0.21 & 26.17 & $<0.001$ \\
AAR (\%LVM) & 0.46 & 0.20 & 0.39 & $<0.001$ \\
LAD IRA & 0.39 & 0.15 & - & 0.001 \\
Reperfusion method & 0.39 & 0.15 & - & 0.003 \\
TIMl grade post-PCl & 0.32 & 0.09 & -8.23 & 0.006 \\
Time from admission to CMR (d) & 0.29 & 0.07 & 4.62 & 0.01 \\
TIMl grade pre-PCl & 0.15 & 0.01 & -2.74 & 0.22
\end{tabular}

\section{Multivariate}

(Strongest model $=T T R+A A R+\angle A D I R A+$

Reperfusion method + TIMI post + Time

from admission to $(M R)$ :

$\begin{array}{lll}T_{T R} \text { (mins) }^{a} & 17.72 & 0.02 \\ \text { AAR (\%LVM) } & 0.23 & 0.02 \\ \text { TIMI grade post-PCI } & -5.21 & 0.04 \\ \text { LAD IRA } & 6.49 & 0.10 \\ \text { Time from admission to CMR (d) } & 2.54 & 0.12 \\ \text { Lysis v PPCl } & -8.60 & 0.08 \\ \text { R-PCI v PPCl } & 6.45 & 0.27 \\ \text { Late PCI v PPCl } & -7.05 & 0.45\end{array}$

$\mathrm{PCl}=$ percutaneous coronary intervention, $\mathrm{TTR}=$ time from symptom onset to revascularisation, $A A R=$ ischaemic area at risk (\%LV mass), IRA = infarct-related artery, $\mathrm{LAD}=$ left anterior descending artery, $\mathrm{TIMI}=$ thrombolysis in myocardial infarction, $\mathrm{R}-\mathrm{PCl}=$ rescue $\mathrm{PCl}$.

analysed using Log10 transformed data.

Table 4 Predictors of MVO extent in reperfused patients

\begin{tabular}{|c|c|c|c|c|}
\hline Dependent variable for MVO & $r$ & $\mathrm{R}^{2}$ & B & $\mathbf{p}$ \\
\hline \multicolumn{5}{|l|}{ Univariate } \\
\hline$\pi \mathrm{R}(\operatorname{mins})^{\mathrm{a}}$ & 0.37 & 0.13 & 0.27 & 0.001 \\
\hline AAR (\%LVM) & 0.39 & 0.14 & 0.004 & 0.001 \\
\hline Reperfusion method & 0.40 & 0.13 & - & 0.008 \\
\hline TIMI grade pre-PCI & 0.35 & 0.08 & -0.32 & 0.03 \\
\hline TIMl grade post-PCl & 0.32 & 0.06 & -0.98 & 0.06 \\
\hline LAD IRA & 0.16 & 0.01 & - & 0.18 \\
\hline Time from admission to CMR (d) & 0.12 & 0.01 & 0.02 & 0.33 \\
\hline
\end{tabular}

\section{Multivariate}

(Strongest model $=T T R+A A R+T I M I$ post)

AAR (\%LVM)

$0.003 \quad 0.01$

TIMl grade post-PCl

$\mathrm{PCl}=$ percutaneous coronary intervention, $\mathrm{TT}=$ time from symptom onset to revascularisation, IRA = infarct-related artery, $\mathrm{LAD}=$ left anterior descending artery, $\mathrm{TIMI}=$ thrombolysis in myocardial infarction, $\mathrm{AAR}=$ ischaemic area at risk (\%LV mass).

analysed using Log10 transformed data.
Table 5 CMR data for early reperfused versus nonreperfused patients

\begin{tabular}{llll}
\hline Variable & $\begin{array}{l}\text { Early reperfused } \\
(\mathbf{n}=\mathbf{5 9})\end{array}$ & $\begin{array}{l}\text { Non-reperfused } \\
(\mathbf{n}=\mathbf{2 1})\end{array}$ & $\mathbf{p}$ \\
\hline Age (y) & $60.2 \pm 11.9$ & $65.6 \pm 16.2$ & 0.11 \\
Male sex (\%) & $53(89.8)$ & $16(76.2)$ & 0.12 \\
Time admission-CMR (d) & $1.9(1.2-2.6)$ & $6.6(4.8-11.0)$ & $<0.001$ \\
LVEDVI (ml/m2) & $90.7(82.4-102.7)$ & $98.0(88.1-125.0)$ & 0.005 \\
LVESVI (ml/m2) & $51.4(45.4-62.6)$ & $61.1(54.0-83.6)$ & 0.002 \\
EF (\%) & $42.3 \pm 7.8$ & $35.0 \pm 11.3$ & 0.002 \\
IS (\%LVM) & $24.4 \pm 15.3$ & $23.8 \pm 11.5$ & 0.87 \\
MVO prevalence (n,\%) & $33(55.9 \%)$ & $15(71.4 \%)$ & 0.21 \\
MVO (\%LVM) & $0.4(0.0-2.9)$ & $1.3(0.0-2.8)$ & 0.36 \\
\hline PPCI = prima
\end{tabular}

$\mathrm{PPCl}=$ primary percutaneous coronary angioplasty, LVEDVI = left ventricular end-diastolic volume-index, LVESVI = left ventricular end-systolic volume-index, LVEDMI = left ventricular end-diastolic mass, LVEF = left ventricular ejection fraction, IS = infarct size (\%LV mass), MVO = microvascular obstruction (\%LV mass).

LVEF lower in the non-reperfused group compared to the early-reperfused group. IS was similar in the two groups despite CMR being performed later in the non-reperfused group. The prevalence and extent of MVO was similar in the two groups. Representative CMR and angiographic images from patients within our 5 study groups are shown in Figure 3.

\section{Discussion}

Microvascular obstruction is widely regarded as a manifestation of reperfusion injury after STEMI $[1-3,16,17]$. Here, we demonstrate that MVO occurs frequently in all forms of reperfusion therapy for STEMI, but also in those presenting late, receiving no specific reperfusion therapy. Although IS and the extent of MVO appeared to be greatest in those receiving reperfusion late (R-PCI or late $\mathrm{PCI}]$ ), this difference was not statistically significant when adjusted for TTR, an important determinant of IS $[18,19]$ and prognosis [20] following PPCI. Indeed, there was a similar prevalence and trend towards increased extent of MVO in patients receiving no reperfusion therapy compared with those undergoing timely reperfusion. Our findings suggest that in real-life clinical patients presenting with STEMI, CMR-measured MVO is primarily an ischaemic injury rather than a reperfusion injury per se. This may have implications for currently planned and future trials in PPCI assessing therapies specifically designed to reduce reperfusion injury.

\section{CMR-MVO and reperfusion injury}

'No-reflow' was first demonstrated in canine myocardium in 1974 [3], and is characterized by ultrastructural changes secondary to severe microvascular injury $[1,16]$. MVO is generally assumed to be primarily related to reperfusion injury $[1-3,16,17]$. Animal studies have demonstrated infarct 
expansion and an almost three-fold increase in MVO extent in the first 48 hours post reperfusion, and a corresponding reduction in regional blood-flow to $<45 \%$ of that pre-ischaemia, after 2 minutes of hyperaemia [21,22]. Reperfusion has been postulated to contribute to MVO through embolization of debris [23], release of vasoconstrictor and inflammatory substances (e.g. serotonin, thromboxane-B) [24] and mechanical damage to the capillary bed [16].

MVO is visualised on CMR by first-pass perfusion, early gadolinium imaging and LGE imaging as hypoenhanced areas within infarct cores [9] and is seen in up to $60 \%$ of PPCI patients post STEMI [25]. LGE-derived MVO ('late $\mathrm{MVO}^{\prime}$ ) is felt to be the most important measure of MVO because of its strong correlation with ST-segment resolution, adverse ventricular remodeling [5] and major adverse cardiovascular events $[9,26]$. In both experimental models [27] and in patients treated by PPCI there is a strong correlation between MVO extent and IS on CMR [28,29].

Consistent with an extensive evidence base demonstrating correlation between the duration of ischaemia (TTR) and the extent of myocardial injury, our non-reperfused cohort had larger LV volumes and lower LVEF [18,19] compared with those promptly reperfused. CMR was performed later in the non-reperfused group. The extent of IS and MVO measured by CMR is known to decrease during the first week following treatment for STEMI (IS: reduction of $\sim 21-30 \%$ in humans [30,31]; MVO: reduction of $\sim 48 \%$ in humans [30], $\sim 67 \%$ in animals [32]). It is therefore likely that had CMR been undertaken at a similar time-point after admission in non-reperfused and early-reperfused patients, the extent of IS and MVO may have been significantly greater in the non-reperfused cohort. Importantly, the FWHM technique requires minor operator input and results in extremely high intra- and interobserver agreement for quantification of MVO.

Our data suggest that CMR-measured MVO should not be used as a surrogate of subclinical angiographic 'no-reflow' or as a specific marker of reperfusion injury. Reperfusion injury is one component contributing to overall IS, $[16,17]$ but in real-world patients presenting typically 2-3 hours after symptom onset with STEMI, the contribution of reperfusion to overall injury may be impossible to assess. Our data clearly show that CMR-measured MVO is extremely prevalent in nonreperfused patients and like IS, is strongly related to TTR and AAR in those receiving reperfusion therapy. This finding casts doubt on the selection of MVO, as opposed to IS or myocardial salvage index, as the primary CMR-based outcome in clinical trials that specifically aim to reduce reperfusion injury. As TTR is strongly related to IS and MVO, the potential to ameliorate true reperfusion injury will be greatest in those who have less ischaemic injury at the time of P-PCI, and short duration of symptoms, e.g. $<3$ hours from symptom onset may be where the benefit of effective treatments will be realised $[20,27,28]$.

\section{Myocardial and microvascular damage by revascularisation strategy}

CMR characteristics were similar with PPCI and thrombolysis, consistent with Bodi who demonstrated no differences in LV volumes, LVEF, IS, MVO or myocardial salvage index (MSI) [11]. The small number of late-PCI and R-PCI patients make statistical comparisons difficult. Our observations are similar to Ruiz-Nodar who demonstrated only $9 \%$ MSI with R-PCI [33], and the MERLIN study demonstrated similar LV function at 30 days in R-PCI compared with conservatively treated patients [34]. The current evidence base demonstrates a lack of prognostic benefit with late PCI [35]. All late PCI patients in our study had LAD infarcts and tended to be younger, factors likely to influence the clinical decision to proceed to intervention. The LAD IRA is likely to account for their larger AAR. The effects of R-PCI and late PCI on reducing LV myocardial and microvascular damage in STEMI remain unclear.

\section{Limitations}

Patients were not randomized. The non-reperfused group were retrospectively identified and underwent CMR later than patients receiving reperfusion, however this difference should underestimate both the prevalence and extent of MVO in this group. The numbers of patients being treated with late PCI and R-PCI are small and no definitive conclusions can be drawn on the infarct characteristics.

\section{Conclusions}

CMR-derived MVO is highly prevalent in STEMI patients not receiving reperfusion therapy. CMR measured MVO is more closely related to ischaemic time than reperfusion therapy in STEMI and may not be a good surrogate marker of reperfusion injury.

\section{Competing interests \\ The authors declare that they have no competing interests.}

\section{Authors' contributions}

GPM, IBS and AHG conceived the idea for the study and developed the protocol. NR and GPM recruited patients and were present at study visits. JNK and NR performed the CMR analyses. JNK performed the angiographic analysis. JNK and NGDM performed the statistical analysis. JNK wrote the paper, which all authors critically reviewed for content. All authors read and approved the final manuscript.

\section{Funding}

GPM is supported by a National Institute for Health Research (NIHR) Postdoctoral Research Fellowship. This work is part of a project grant funded by the British Heart Foundation with support from the NIHR Leicester Cardiovascular Biomedical Research Unit.

Received: 27 March 2014 Accepted: 14 May 2014

Published: 27 May 2014 


\section{References}

1. Wu KC. Cmr of microvascular obstruction and hemorrhage in myocardial infarction. JCMR. 2012; 14:68

2. Eeckhout E, Kern MJ. The coronary no-reflow phenomenon: a review of mechanisms and therapies. Eur Heart J. 2001; 22:729-39.

3. Kloner RA, Ganote $C E$, Jennings RB. The "no-reflow" phenomenon after temporary coronary occlusion in the dog. J Clin Invest. 1974; 54:1496-508.

4. Klem I, Shah DJ, White RD, Pennell DJ, van Rossum AC, Regenfus M, Sechtem U, Schvartzman PR, Hunold P, Croisille P, Parker M, Judd RM, Kim RJ. Prognostic value of routine cardiac magnetic resonance assessment of left ventricular ejection fraction and myocardial damage: an international, multicenter study. Circ Cardiovasc Imaging. 2011; 4:610-19.

5. Nijveldt R, Beek AM, Hirsch A, Stoel MG, Hofman MB, Umans VA, Algra PR, Twisk JW, van Rossum AC. Functional recovery after acute myocardial infarction: comparison between angiography, electrocardiography, and cardiovascular magnetic resonance measures of microvascular injury. J Am Coll Cardiol. 2008; 52:181-89.

6. Hombach V, Grebe O, Merkle N, Waldenmaier S, Höher M, Kochs M, Wöhrle J, Kestler $\mathrm{H}$. Sequelae of acute myocardial infarction regarding cardiac structure and function and their prognostic significance as assessed by magnetic resonance imaging. Eur Heart J. 2005; 26:549-57.

7. Wu E, Ortiz JT, Tejedor P, Lee DC, Kansal P, Carr JC, Holly TA, Klocke FJ, Bonow $\mathrm{RO}$. Infarct size by contrast enhanced cardiac magnetic resonance is a stronger predictor of outcomes than left ventricular ejection fraction or end-systolic volume index: prospective cohort study infarct size by contrast enhanced cardiac magnetic resonance i. Heart. 2008; 94:730-36.

8. Klug G, Mayr A, Schenk S, Esterhammer R, Schocke M, Jaschke W, Pachinger $\mathrm{O}$, Metzler B. Prognostic value at 5 years of microvascular obstruction after acute myocardial infarction assessed by cardiovascular magnetic resonance. J Cardiovasc Magn Reson. 2012; 14:46.

9. de Waha S, Desch S, Eitel I, Fuernau G. Impact of early vs Late microvascular obstruction assessed by magnetic resonance imaging on longterm outcome after st-elevation myocardial infarction: a comparison with traditional prognostic markers. Eur Heart J. 2010; 31:2660-68.

10. Steg PG, James SK, Atar D, Badano LP, Lundqvist CB, Borger MA, Di Mario C, Dickstein K, Ducrocq G, Fernandez-Aviles F, Gershlick AH, Giannuzzi P, Halvorsen S, Huber K, Juni P, Kastrati A, Knuuti J, Lenzen MJ, Mahaffey KW, Valgimigli M, Van't Hof A, Widimsky P, Zahger D, Bax JJ, Baumgartner H, Ceconi C, Dean V, Deaton C, Fagard R, Funck-Brentano C, et al. Esc guidelines for the management of acute myocardial infarction in patients presenting with st-segment elevation: the task force on the management of stsegment elevation acute myocardial infarction of the european society of cardiology (esc). Eur Heart J. 2012; 33(20):2569-619.

11. Bodi V, Rumiz E, Merlos P, Nunez J, Lopez-Lereu MP, Monmeneu JV, Chaustre F, Moratal D, Trapero I, Blasco ML, Oltra R, Sanjuan R, Chorro FJ, Llacer A, Sanchis J. One-week and 6-month cardiovascular magnetic resonance outcome of the pharmacoinvasive strategy and primary angioplasty for the reperfusion of st-segment elevation myocardial infarction. Rev Esp Cardiol. 2011; 64:111-20.

12. Thiele H, Eitel I, Meinberg C, Desch S, Leuschner A, Pfeiffer D, Hartmann A, Lotze U, Strauss W, Schuler G. Randomized comparison of pre-hospitalinitiated facilitated percutaneous coronary intervention versus primary percutaneous coronary intervention in acute myocardial infarction very early after symptom onset: the lipsia-stemi trial (leipzig immediate preho). JACC Cardiovasc Interv. 2011; 4:605-14.

13. TIMI-Collaborators. The thrombolysis in myocardial infarction (timi) trial. Phase i findings. Timi study group. N Engl J Med. 1985; 312:932-36

14. Rentrop KP, Cohen M, Blanke H, Phillips RA. Changes in collateral channel filling immediately after controlled coronary artery occlusion by an angioplasty balloon in human subjects. J Am Coll Cardiol. 1985: 5:587-92.

15. Flett AS, Hasleton J, Cook C, Hausenloy D, Quarta G, Ariti C, Muthurangu V, Moon JC. Evaluation of techniques for the quantification of myocardial scar of differing etiology using cardiac magnetic resonance. JACC Cardiovasc Imaging. 2011; 4:150-56.

16. Frohlich GM, Meier P, White SK, Yellon DM, Hausenloy DJ. Myocardial reperfusion injury: looking beyond primary pci. Eur Heart J. 2013; 34:1714-22.

17. Yellon DM, Hausenloy DJ. Myocardial reperfusion injury. N Engl J Med. 2007: 357:1121-35
18. Francone M, Bucciarelli-Ducci C, Carbone I, Canali E, Scardala R, Calabrese F, Sardella G, Mancone M, Catalano C, Fedele F, Passariello R, Bogaert J, Agati L. Impact of primary coronary angioplasty delay on myocardial salvage, infarct size, and microvascular damage in patients with st-segment elevation myocardial infarction: insight from cardiovascular magnetic resonance. J Am Coll Cardiol. 2009; 54:2145-53.

19. Hedström E, Engblom H, Frogner F, Åström-olsson K, Öhlin H, Jovinge S, Arheden $\mathrm{H}$. Infarct evolution in man studied in patients with first-time coronary occlusion in comparison to different species - implications for assessment of myocardial salvage. J Cardiovasc Magn Reson. 2009; 10:1-10.

20. Gersh BJ, Stone GW, White HD, Holmes DR Jr. Pharmacological facilitation of primary percutaneous coronary intervention for acute myocardial infarction: is the slope of the curve the shape of the future? JAMA. 2005; 293:979-86.

21. Rochitte CE, Lima JAC, Bluemke DA, Reeder SB, Elliot R, Furuta T, Becker LC, Melin JA. Magnitude and time course of microvascular obstruction and tissue injury after acute myocadial infarction. Circulation. 1998; 98:1006-14.

22. Reffelmann T, Kloner RA. Microvascular reperfusion injury: rapid expansion of anatomic no reflow during reperfusion in the rabbit. Am J Physiol Heart Circ Physiol. 2002; 283:H1099-107.

23. Heusch G, Kleinbongard P, Bose D, Levkau B, Haude M, Schulz R, Erbel R. Coronary microembolization: from bedside to bench and back to bedside. Circulation. 2009; 120:1822-36.

24. Kleinbongard P, Bose D, Baars T, Mohlenkamp S, Konorza T, Schoner S, ElterSchulz M, Eggebrecht H, Degen H, Haude M, Levkau B, Schulz R, Erbel R, Heusch $G$. Vasoconstrictor potential of coronary aspirate from patients undergoing stenting of saphenous vein aortocoronary bypass grafts and its pharmacological attenuation. Circ Res. 2011; 108:344-52.

25. Bogaert J, Kalantzi M, Rademakers FE, Dymarkowski S, Janssens S. Determinants and impact of microvascular obstruction in successfully reperfused st-segment elevation myocardial infarction. Assessment by magnetic resonance imaging. Eur Radiol. 2007; 17:2572-80.

26. de Waha S, Desch S, Eitel I, Fuernau G, Lurz P, Leuschner A, Grothoff M, Gutberlet M, Schuler $G$, Thiele H. Relationship and prognostic value of microvascular obstruction and infarct size in st-elevation myocardial infarction as visualized by magnetic resonance imaging. Clin Res Cardiol. 2012; 101(6):487-95.

27. Gerber BL, Rochitte CE, Melin JA, Mcveigh ER, Bluemke A, Wu KC, Becker $L C$, Lima JAC. Microvascular obstruction and left ventricular remodelling early after acute myocardial infarction. Circulation. 2000; 101:2734-41.

28. Amabile N, Jacquier A, Gaudart J, Sarran A, Shuaib A, Panuel M, Moulin G, Bartoli J-m, Paganelli F. Value of a new multiparametric score for prediction of microvascular obstruction lesions in st-segment elevation myocardial infarction revascularized by percutaneous coronary intervention. Arch Cardiovasc Dis. 2010; 103:512-21.

29. Ørn S, Manhenke C, Greve OJ, Larsen Al, Bonarjee WV, Edvardsen T, Dickstein K. Microvascular obstruction is a major determinant of infarct healing and subsequent left ventricular remodelling following primary percutaneous coronary intervention. Eur Heart J. 2009; 30:1978-85.

30. Mather AN, Fairbairn TA, Artis NJ, Greenwood JP. Timing of cardiovascular mr imaging after acute myocardial infarction: effect on estimates of infarct characteristics and prediction of late ventricular remodeling. Radiology. 2011; 261:116-26.

31. Ibrahim T, HackI T, Nekolla SG, Breuer M, Feldmair M, Schömig A. Acute myocardial infarction: serial cardiac mr imaging shows a decrease in delayed enhancement of the myocardium during the 1st week after reperfusion. Radiology. 2010; 254:88-97.

32. Ghugre NR, Pop M, Barry J, Connelly KA, Wright GA. Quantitative magnetic resonance imaging can distinguish remodeling mechanisms after acute myocardial infarction based on the severity of ischemic insult. Magn Reson Med. 2013; 70(4):1095-105.

33. Ruiz-Nodara J, Feliub E, Sánchez-Quiñonesa J, Valencia-Martína J, Garcíab M, Pinedaa J, Martínb P, Mainara V, Bordesa P, Herasa S, Quintanillaa MA, Sogor F. Minimum salvaged myocardium after rescue percutaneous coronary intervention: quantification by cardiac magnetic resonance. Rev Esp Cardiol. 2011; 64:965-71. 
34. Sutton AG, Campbell PG, Graham R, Price DJ, Gray JC, Grech ED, Hall JA, Harcombe AA, Wright RA, Smith RH, Murphy JJ, Shyam-Sundar A, Stewart MJ, Davies A, Linker NJ, de Belder MA. A randomized trial of rescue angioplasty versus a conservative approach for failed fibrinolysis in st-segment elevation myocardial infarction: the middlesbrough early revascularization to limit infarction (merlin) trial. J Am Coll Cardiol. 2004; 44:287-96.

35. loannidis JP, Katritsis DG. Percutaneous coronary intervention for late reperfusion after myocardial infarction in stable patients. Am Heart $\mathrm{J}$. 2007; 154:1065-71.

doi:10.1186/1532-429X-16-38

Cite this article as: Khan et al:: Prevalence and extent of infarct and

microvascular obstruction following different reperfusion therapies in

ST-elevation myocardial infarction. Journal of Cardiovascular Magnetic

Resonance 2014 16:38.

\section{Submit your next manuscript to BioMed Central and take full advantage of:}

- Convenient online submission

- Thorough peer review

- No space constraints or color figure charges

- Immediate publication on acceptance

- Inclusion in PubMed, CAS, Scopus and Google Scholar

- Research which is freely available for redistribution 